\title{
Large spatial variability in lifetime egg production in an intertidal Baltic tellin (Macoma balthica) population
}

Received: 15 April 2002 / Revised: 27 September 2002 / Accepted: 4 October 2002 / Published online: 3 December 2002 C) Springer-Verlag and AWI 2002

\begin{abstract}
The extent to which it pays settling larvae of marine benthic organisms to actively select the habitat where they will spend the rest of their life can only be fully appreciated if the fitness consequences of such habitat selection processes are known. We estimated the lifetime egg production of the tellinid bivalve Macoma balthica at 11 sites over a tidal gradient in the western Wadden Sea, using a 30-year data series. The difference in individual lifetime egg production between the best sites in the lower tidal zone and the poorest sites on the high tidal flats was about a factor 10 . The differences in lifetime egg production were related to differences in growth and, more importantly, survival. We argue that the large observed differences in reproductive output do not necessarily imply a lack of active habitat selection. As most animals start their last migration before final settlement from the high tidal flats, the choice may be one between a long and risky migration with a low chance of reaching the good habitat versus a more certain but poor existence on the high tidal flats.
\end{abstract}

Keywords Macoma balthica . Sink-source populations . Lifetime reproductive success $\cdot$ Soft sediments

\section{Introduction}

Animals live in spatially heterogeneous environments. The spatial variability in habitat quality may be reflected in the performance, in terms of survival and reproduction, of the individuals. Differences in performance may have consequences for the dynamics of the spatiallystructured population (Kluyver and Tinbergen 1953; Tilman and Kareiva 1997). Source-sink models, for ex-

Communicated by W. Armonies, M. Strasser and K. Reise

J. van der Meer $(-$ J.J. Beukema $\cdot$ R. Dekker

Royal Netherlands Institute for Sea Research (NIOZ), PO Box 59, 1790 AB Den Burg, Texel, The Netherlands

e-mail: e-mail: meer@nioz.nl

Tel.: +31-222-369357, Fax: +31-222-319674 ample, consider the presence of large spatial variability in habitat quality and assume that poor habitats, where mortality exceeds natality, act as sinks and require the input of surplus individuals produced in the source habitats (Pulliam 1988; Dias 1996).

If one considers the individual level, the idea that animals perform better in some habitats than in others contradicts the predictions of ideal free theory. This theory says that animals will distribute themselves over habitats of different quality in such a way that fitness is equal (Fretwell and Lucas 1970). The additional assumption that the presence of more animals in a habitat leads to lower individual fitness, means that poor habitats will contain relatively few animals, which nevertheless perform just as well as those occurring in the highly crowded high-quality habitats.

There are several reasons why the distribution of animals will not obey the ideal free distribution. One reason is the pre-emption of high quality habitats by competitively dominant individuals. Individuals of lower rank might be unable to intrude into a habitat already occupied, leading to an ideal despotic distribution (Fretwell and Lucas 1970). Another reason could be the inability to actively select the preferred habitat, for example due to passive dispersal as in plant seeds (Keddy 1981).

Many invertebrates living in marine benthic habitats have planktonic larvae, which spend some time in the water column before metamorphosis and settlement on the seafloor. Although many studies have described the ability of marine larvae to delay metamorphosis until a suitable habitat is encountered (Scheltema 1986; Woodin 1991) and the ability for selective tidal-stream transport by vertical migration (Forward and Tankersley 2001), not much is known about the consequences of such abilities in terms of optimal habitat choice. The true variability in quality of the habitats where the animals eventually settle, and the resulting spatial variability in egg production or reproductive success during the sessile phase of life, remain largely unknown. One of the reasons for this ignorance is that short-term spatial studies are not appropriate. Random variability cannot be ignored, which 
means that the average quality of a site may not become evident from a 1-year study. Hence, long-term studies are required.

In this study we use spatio-temporal data on the demography and growth of a benthic population of the tellinid bivalve Macoma balthica (L.) in the western Wadden Sea, The Netherlands, obtained over a long period of about 30 years. We estimate the spatial variability in various components of lifetime egg production (longevity, growth, fecundity), and explore the relationship between habitat choice and lifetime egg production.

\section{Methods}

Study area

Balgzand is a tidal-flat area in the westernmost part of the Wadden Sea, The Netherlands. The area ranges from a coastal area above mean-tide level with silty sediments to a low exposed area close to low-tide level $(80 \mathrm{~cm}$ below mean-tide level) that emerges a few hours at most and only when strong easterly winds prevail. The area that regularly emerges is about $45 \mathrm{~km}^{2}$ in extent. More details are given in Beukema (1988) and Beukema et al. (1993).

\section{Life history}

The bivalve Macoma balthica (Tellinidae) is one of the most common macrobenthic species on the tidal flats in the western Wadden Sea. The adult stage occurs at high densities of tens to hundreds per square metre (Beukema 1976; Dankers and Beukema 1983). Initial settlement of post-larvae in spring, at a size of approximately $280 \mu \mathrm{m}$, takes place mainly in the lower half of the intertidal (Günther 1991; Armonies and Hellwig-Armonies 1992; Beukema 1993). Some weeks later, the juveniles occur in maximal numbers on the higher tidal flats, above mean-tide level (Dankers and Beukema 1983; Günther 1991; Armonies and Hellwig-Armonies 1992; Beukema 1993). In the subsequent winter most animals move to the middle and lower zones, where they settle again and will spend the rest of their life (Beukema and De Vlas 1989; Beukema 1993). We thus assumed that the Baltic tellin is sedentary after the first winter. This assumption was confirmed by surveys with plankton nets suspended in tidal streams in the Wadden Sea (Beukema and De Vlas 1989) and by studies on the recolonization of large defaunated areas (Beukema et al. 1999). In both cases no adults, but only post-larvae and juvenile Baltic tellins, were observed.

In the present analysis, the term recruit density refers to the abundance of the zero-year class at the end of their first winter, when the second settlement phase is (almost) completed. Hence our definition of recruitment separates the highly mobile first life phase from the more or less sessile later part of life.

\section{Sampling and data selection}

Between 1970 and 1998, 12 randomly selected stations, each in the form of a 1-km-long transect, have been sampled at the tidal flats of Balgzand each year in late winter (March). The geographical position of each station was determined by a starting point and a wind direction, which were randomly chosen from a grid of geographical coordinates and a set of angles, respectively. One station near the tidal channel, which rarely emerges, was not taken into account in the present paper because densities of M. balthica were too low to get reliable estimates of, for example, mortality rates. At each station 50 cores of $0.019 \mathrm{~m}^{2}$ were taken at a regular distance of $20 \mathrm{~m}$ between two cores. All cores were taken to a depth of $30 \mathrm{~cm}$ and immediately washed through a $1 \mathrm{~mm}$ sieve. Shells of
$M$. balthica were aged by counting the narrow dark year-rings that indicated interruption of shell growth (Lammens 1967).

Numerical density $Y$, biomass density $B$, and average length $L$ were determined separately for each year-class (0-4 and 5+). Only data for the cohorts born in the years 1969-1992 were used because they could be followed from age class 0 up to age class 5 . More details of the sampling procedure are given in Beukema (1974). In the remaining part of the paper, all biomass data refer to ash-free dry biomass.

For each site, the altitude was derived from detailed maps (Rijkswaterstaat, Ministry of Transport and Public Works), which were available for the years 1980 and 1991, and the average of these two figures was used as an estimate of the intertidal height of each site.

Estimating growth, mortality, condition and lifetime reproductive success

For each cohort, cohort $i=1969, \ldots, 1992$, at each site, site $k=$ $1, \ldots, 11$, non-linear regression was used to estimate the asymptotic length $\mathrm{L}_{\infty}, i_{k}$ and the growth coefficient $\gamma_{i k}$ using the Von Bertalanffy length growth curve. Similarly, for each cohort, at each site, log-linear Poisson regression was used for estimating the initial cohort density $\mu_{i k}$ and mortality rate $\lambda_{i k}$ using an exponential survival curve. Finally, a condition parameter $\phi_{i k}$, which equals the individual mass to cubic shell length ratio, was estimated for each cohort $i$, at each site $k$. Details of the estimation procedures are given in van der Meer et al. (2001).

Annual egg production per individual $\mathrm{y}_{i j k}$ (cohort $i$, age-class $j$, site $k$ ) was estimated on the basis of the following relationship (Honkoop et al. 1998):

$y_{i j k}=\alpha \frac{l_{i j k}^{3}}{s^{3}}\left(x_{i j k}-\beta\right)$

and for each site-cohort combination the overall egg production equals the annual egg production summed over all age classes, which could be estimated by

$y_{i k}=\sum_{j=2}^{6} \frac{n_{i j k}}{2} y_{i j k}=\sum_{j=2}^{6} \frac{n_{i j k}}{2} \alpha \frac{l_{i j k}^{3}}{s^{3}}\left(x_{i j k}-\beta\right)$

where $n_{i j k}$ is the numerical density $\left(\mathrm{m}^{-2}\right), l_{i j k}$ length $(\mathrm{cm}), x_{i j k}$ BMI $\left(\mathrm{mg} / \mathrm{cm}^{3}\right)$, and $s$ the standard length of $1.5 \mathrm{~cm}$. The parameter estimates for $\alpha\left(7,739 \mathrm{~cm}^{3} / \mathrm{mg}\right)$ and $\beta\left(5.6 \mathrm{mg} / \mathrm{cm}^{3}\right)$ were taken from Honkoop and van der Meer (1997). Site-cohort-age groups with a length lower than $1 \mathrm{~cm}$ or a BMI lower than $5.6 \mathrm{mg} / \mathrm{cm}^{3}$ were assumed not to produce eggs.

Estimates per site were obtained by simple averaging over all 24 cohorts, and the accompanying $95 \%$ confidence intervals were based on $23 d f$. The overall estimate was obtained by subsequently averaging the estimates per site.

\section{Results}

Growth, survival, and condition

The performance in terms of condition, growth (maximum length), and mortality differed significantly among sites (Table 1). The variability among sites was large for the instantaneous mortality rate, both in terms of the fraction of the total variance explained (Table 1) and in the coefficient of variation (Table 2). The among-site variability in the condition coefficient (the biomasscubic length ratio), in the asymptotic length and particularly in the Von Bertalanffy growth coefficient was much smaller (Table 2). Mortality rate, asymptotic length and 

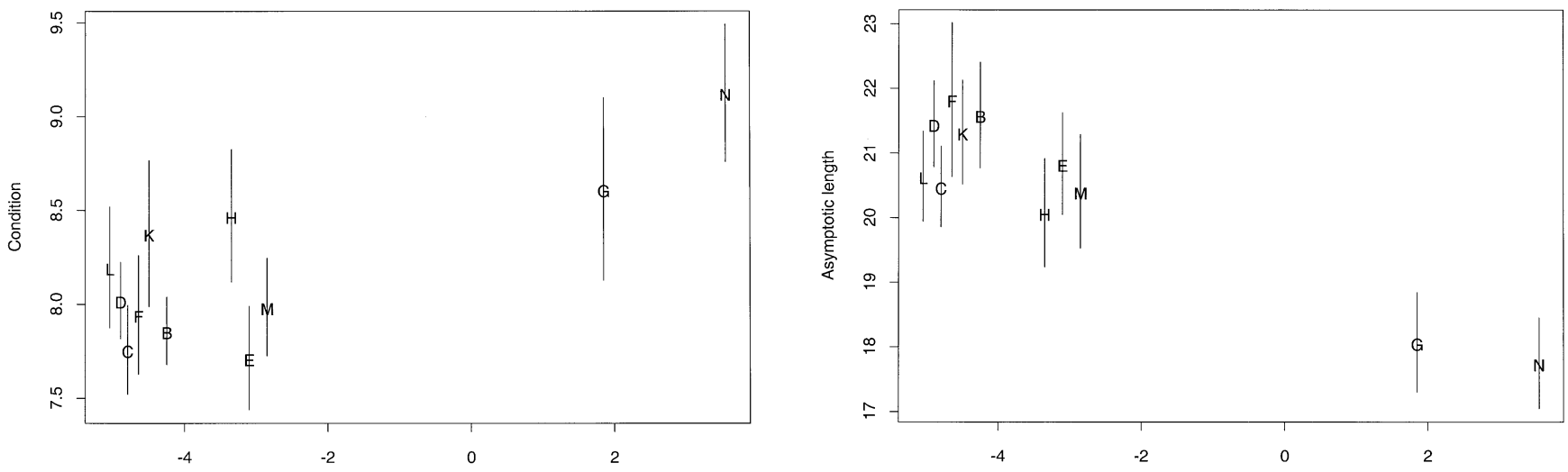

a

altitude

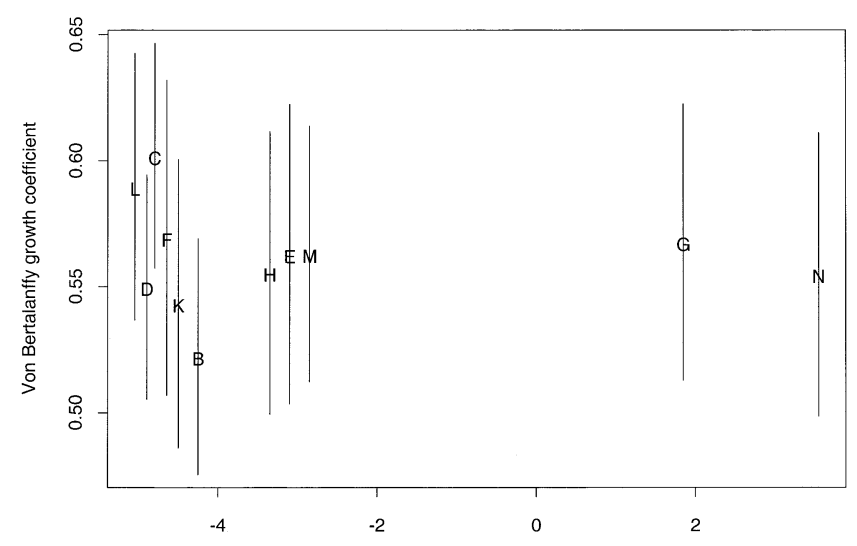

c

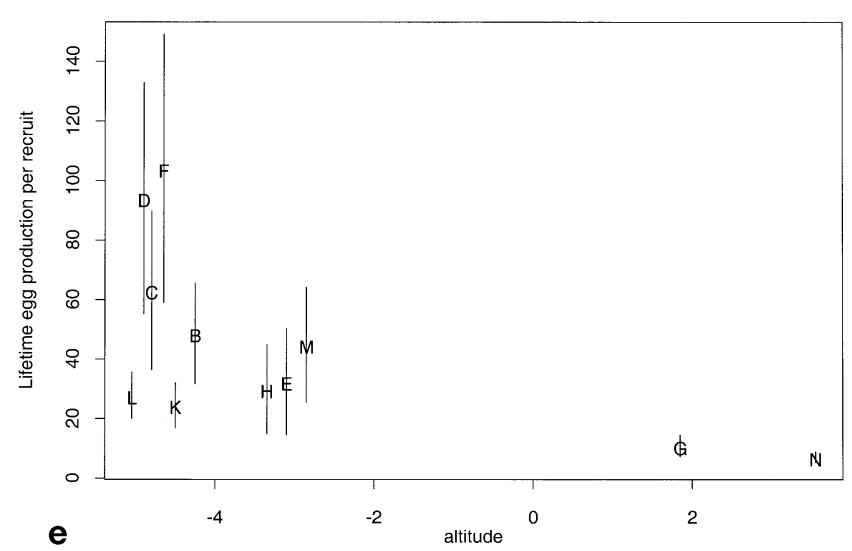

Fig. 1 For each site, estimated means including 95\% confidence intervals of: a condition $\phi\left(\mathrm{kg} \mathrm{m}^{-3}\right)$; b asymptotic length $\mathrm{L}_{\infty}(\mathrm{mm})$; c Von Bertalanffy growth coefficient $\gamma\left(\mathrm{a}^{-1}\right)$; $\mathbf{d}$ instantaneous mortality rate $\lambda\left(\mathrm{a}^{-1}\right)$; e lifetime egg production per recruit in $1,000 \mathrm{~s}$, and $\mathbf{f}$ recruit density $\left(\mathrm{m}^{-2}\right)$ are plotted against altitude

condition were related to tidal height (Fig. 1). Animals living on the highest parts of the sandflats showed a much lower survival compared with plots at the lower parts. Instantaneous mortality rate was as high as 0.8 per year at the highest site, and lower than 0.2 per year at one of the low-lying sites. The animals at the highest
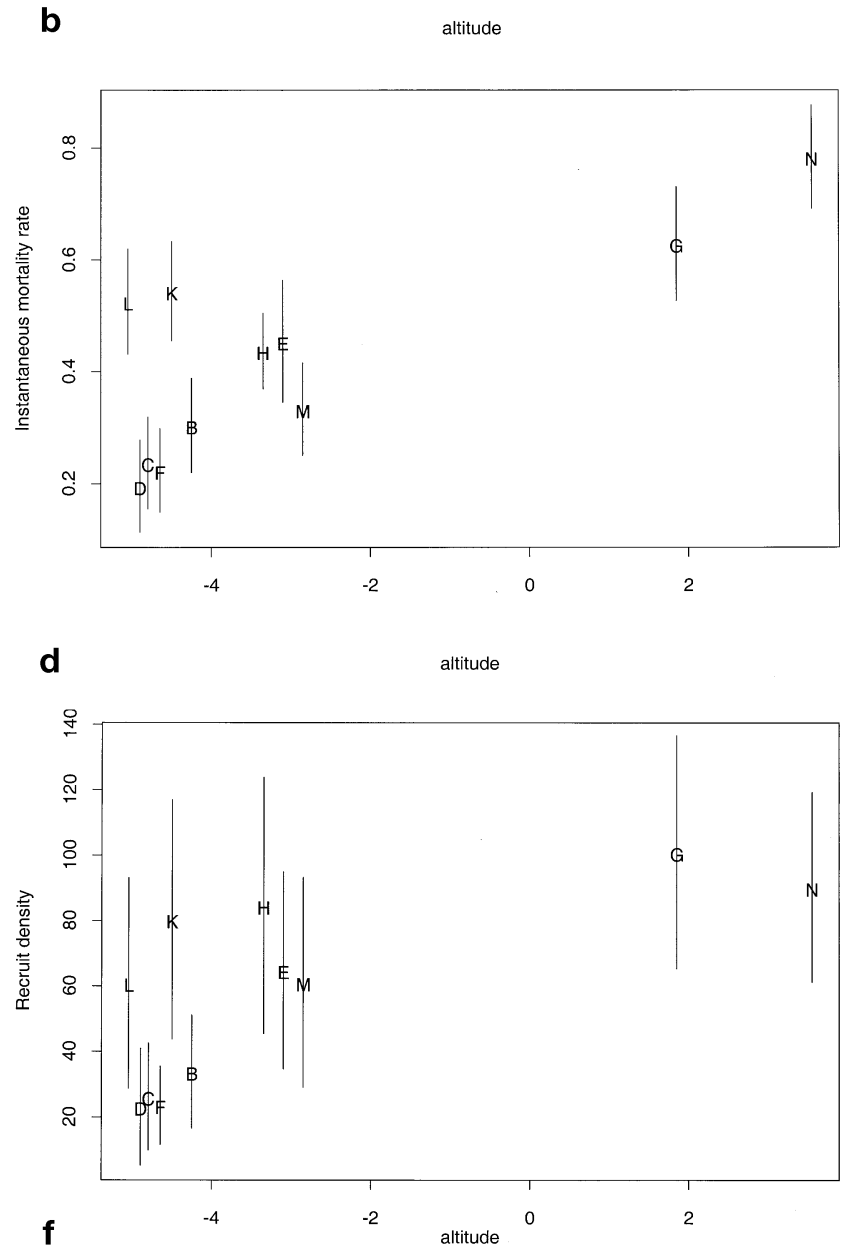

parts also remained smaller (about $17-18 \mathrm{~mm}$ long) than the low-living individuals (between 20 and $22 \mathrm{~mm}$ ). In contrast, the post-winter condition was better on the upper shore.

\section{Average lifetime egg production}

The among-site variability in the average lifetime egg production per recruit was higher than the variability in the separate components of reproductive success, i.e. growth, condition and survival (Table 2, Fig. 1). The 
Table 1 Two-way analysis of variance of the various parameters: condition $\phi\left(\mathrm{kg} \mathrm{m}^{-3}\right)$, asymptotic length $\mathrm{L}_{\infty}(\mathrm{mm})$, Von Bertalanffy growth coefficient $\gamma\left(\mathrm{a}^{-1}\right)$, mortality rate $\lambda\left(\mathrm{a}^{-1}\right)$ and egg production per recruit

\begin{tabular}{lllllll}
\hline & $d f$ & \multicolumn{2}{l}{$\mathrm{SS}$} & & & \\
\cline { 3 - 6 } & & $\phi$ & $\mathrm{L}_{\infty}$ & $\gamma$ & $\lambda$ & Egg production per recruit \\
\hline Cohort & 23 & $58^{*}$ & $348^{*}$ & $1.43^{*}$ & $3.15^{*}$ & $223 \times 10^{3 *}$ \\
Site & 10 & $44^{*}$ & $437^{*}$ & $0.11^{\mathrm{ns}}$ & $8.33^{*}$ & $238 \times 10^{3 *}$ \\
Error & 230 & 82 & 547 & 2.47 & 7.37 & $468 \times 10^{3}$ \\
\hline
\end{tabular}

Factors cohort (24 levels) and site (11 levels), $n=264, d f$ degrees of freedom, SS Sum of squares, $* P<0.001$, ns $P>0.05$.

\begin{tabular}{lcll}
\hline Parameter & Mean & Standard deviation & Coefficient of variation \\
\hline Condition $(\phi)$ & 8.19 & 0.427 & 0.05 \\
Asymptotic length $\left(\mathrm{L}_{\infty}\right)$ & 20.1 & 1.35 & 0.07 \\
Growth coefficient $(\gamma)$ & 0.562 & 0.021 & 0.04 \\
Mortality rate $(\lambda)$ & 0.424 & 0.186 & 0.44 \\
Recruit density & 59.1 & 28.5 & 0.48 \\
Egg production per recruit & 44.3 & 31.5 & 0.71 \\
\hline
\end{tabular}

Table 2 Mean, standard deviation, and coefficient of variation of the various parameters: condition $\phi\left(\mathrm{kg} \mathrm{m}^{-3}\right)$, asymptotic length $\mathrm{L}_{\infty}(\mathrm{mm})$, Von Bertalanffy growth coefficient $\gamma\left(\mathrm{a}^{-1}\right)$, mortality rate $\lambda\left(\mathrm{a}^{-1}\right)$, recruit density $\left(\mathrm{m}^{-2}\right)$ and egg production per recruit in $1,000 \mathrm{~s}, n=11$ highest estimated egg production was about 100,000 eggs at one of the low-lying sites, whereas the lowest estimated egg production (at the highest altitude) was even less than 10,000 eggs, a tenfold difference.

\section{Discussion}

A large number of studies, mainly on birds and other vertebrates, have dealt with the variability in the total number of offspring produced by recognizable individuals during their entire lifespans (Clutton-Brock 1988; Newton 1989). Some of these studies related the estimated lifetime reproductive success (LRS) to the habitat choice of individuals at the start of their reproductive age (Ens et al. 1995; Conradt et al. 1999). Ens et al. (1995), for example, observed that oystercatchers in territories of high quality, where chicks could be taken to the food, fledged three times as many chicks as those in poor territories where all food had to be transported to the chicks. They further noted that the birds who reached reproductive age were not able to enter a high-quality territory immediately, but had to queue for a few years, with the risk of dying while waiting. Ens et al. (1995) therefore argued that expected LRS should not be estimated from the moment individuals start to breed, but from the time that they have to make the choice between either entering the queue and hoping to obtain a good territory later on or settling immediately in the poor-quality area. An evolutionary equilibrium was possible where the expected success of the two strategies was equal.

For marine benthic invertebrates living in soft sediments, it is at present impossible to follow individuals during their entire lifetime and measure their lifetime reproductive success. However, an indirect approach is possible and was followed here. At each site we studied the fate of 24 separate cohorts, starting directly after the second settlement (Beukema 1993), i.e. immediately following the principal habitat 'choice' of settlers. Each year, just before the time of reproduction, we measured for each cohort the abundance, average size and condition. Using a general relationship between size and condition and egg production (Honkoop and van der Meer 1997), we predicted total egg production. We thus did not measure egg production directly on each occasion, and this may have biased our results. However, the estimated relationship was based on a field data from various sites and years and experimental data from various experiments (Honkoop and van der Meer 1997, 1998). The relationship was also consistent with the result of previous experiments by other researchers (De Wilde and Berghuis 1976; Honkoop et al. 1999).

The various components of reproductive output did not show the same amount of spatial variability. The variability in mortality rate was much larger (CV 0.44), than the variability in the growth parameters and in condition (CVs from 0.04 to 0.07 ). Total egg production per individual also correlated most strongly with mortality rate $\left(r_{\mathrm{s}}=-0.89\right)$, but also with maximum size $\left(r_{\mathrm{s}}=0.70\right)$.

The low growth, high mortality and low reproductive output at the highest parts of the sandflats point to a poor-quality habitat for the adult stage. Oddly enough, recruit density was higher in this harsh environment than in the lower areas. One might argue that the time that we measured recruitment was too early (late February to late March), as the offshore migration continues into April (Beukema and De Vlas 1989). However, even in the succeeding summer sampling (in August and September, several months after the final settlement), the highest densities of the 1-year class were still found on the high (coastal) tidal flats. Thus, although during their first winter many young bottom stages of $M$. balthica are transported in an offshore direction, many others remained in the upper zone where their expected future reproductive output is very low. Staying upshore is not necessarily a maladaptive behaviour, as the animals might be constrained in their ability to move to the good habitats in the lower parts of the intertidal area. The final offshore 
migration might be very risky (Hiddink et al. 2002; Hiddink and Wolff 2002), and the advantages of reaching a good habitat may be cancelled out against the risk of dying during migration or the risk of being transported too far and ending up in the deep gullies, where future prospects may even be lower than those on the high tidal flats.

The options open to $M$. balthica thus resemble the options open to young oystercatchers (Ens et al. 1995). In both systems the animals have to make the choice between a relatively low chance of settling in a good habitat or a certain existence in a poor habitat. At this stage it is too early to describe the conditions under which an evolutionary equilibrium between the two strategies lasts. Further empirical studies are required which focus in more detail on the various migration options, but these studies will only be successful if the risk of movement can be quantified.

Acknowledgements We thank Wim de Bruin and Jaap Zuidewind for help in the field and Theunis Piersma and two anonymous referees for their critical comments on an earlier version of the manuscript.

\section{References}

Armonies W, Hellwig-Armonies M (1992) Passive settlement of Macoma balthica spat on tidal flats of the Wadden Sea and subsequent migration of juveniles. Neth J Sea Res 29:371378

Beukema JJ (1974) Seasonal changes in the biomass of the macrobenthos of a tidal flat area in the Dutch Wadden Sea. Neth J Sea Res 8:94-107

Beukema JJ (1976) Biomass and species richness of the macrobenthic animals living on the tidal flats of the Dutch Wadden Sea. Neth J Sea Res 10:236-261

Beukema JJ (1988) An evaluation of the ABC-method (abundance/biomass comparison) as applied to macrozoobenthic communities living on tidal flats in the Dutch Wadden Sea. Mar Biol 99:425-433

Beukema JJ (1993) Successive changes in the distribution patterns as an adaptive strategy in the bivalve Macoma balthica (L.) in the Wadden Sea. Helgol Meeresunters 47:287-304

Beukema JJ, De Vlas J (1989) Tidal-current transport of threaddrifting postlarval juveniles of the bivalve Macoma balthica from the Wadden Sea to the North Sea. Mar Ecol Prog Ser 52:193-200

Beukema JJ, Essink K, Michaelis H, Zwarts L (1993) Year-to-year variability in the biomass of macrobenthic animals on tidal flats of the Wadden Sea: how predictable is this food source for birds? Neth J Sea Res 31:319-330

Beukema JJ, Flach EC, Dekker R, Starink M (1999) A long-term study of the recovery of the macrozoobenthos on large defaunated plots on a tidal flat in the Wadden Sea. J Sea Res 42:235-254

Clutton-Brock TH (1988) Reproductive success. Chicago University Press, Chicago

Conradt L, Clutton-Brock TH, Guinness FE (1999) The relationship between habitat choice and lifetime reproductive success in female red deer. Oecologia 120:218-224
Dankers N, Beukema JJ (1983) Distributional patterns of macrozoobenthic species in relation to some environmental factors. In: Wolff WJ (ed) Ecology of the Wadden Sea. Balkema, Rotterdam, pp 69-103

De Wilde PAWJ, Berghuis EM (1976) Laboratory experiments on the spawning of Macoma balthica: its implications for production research. In: McLusky DS, Berry J (eds) Physiology and behaviour of marine organisms. Pergamon, Oxford, pp 375384

Dias PC (1996) Sources and sinks in population biology. Trends Ecol Evol 11:326-330

Ens BJ, Weissing FJ, Drent RH (1995) The despotic distribution and deferred maturity: two sides of the same coin. Am Nat 146:625-650

Forward RB, Tankersley RA (2001) Selective tidal-stream transport of marine animals. Oceanogr Mar Biol Annu Rev 39:305-353

Fretwell SD, Lucas HL (1970) On territorial behaviour and other factors influencing habitat distribution in birds. Acta Biotheor 19:16-36

Günther C-P (1991) Settlement of Macoma balthica on an intertidal sandflat in the Wadden Sea. Mar. Ecol Prog Ser 76:73-79

Hiddink JG, Wolff WJ (2002) Changes in distribution and decrease of numbers due to migration of the bivalve Macoma balthica. Mar Ecol Prog Ser 232:117-230

Hiddink JG, Kock RP, Wolff WJ (2002) Active pelagic migrations of the bivalve Macoma balthica are dangerous. Mar Biol 140:1149-1156

Honkoop PJC, Meer J van der (1997) Reproductive output of Macoma balthica populations in relation to winter-temperature and intertidal-height mediated changes of body mass. Mar Ecol Prog Ser 149:155-162

Honkoop PJC, Meer J van der (1998) Experimentally induced effects of water temperature and immersion time on reproductive output of bivalves in the Wadden Sea. J Exp Mar Biol Ecol 220:227-246

Honkoop PJC, Meer J van der, Beukema JJ, Kwast D (1998) Does temperature-influenced egg production predict the recruitment in the bivalve Macoma balthica? Mar Ecol Prog Ser 164:229235

Honkoop PJC, Meer J van der, Beukema JJ, Kwast D (1999) Reproductive investment in the intertidal bivalve Macoma balthica. J Sea Res 41:203-212

Keddy PA (1981) Experimental demography of the sand-dune annual Cakile edentula, growing along an environmental gradient in Nova Scotia. J Ecol 69:615-630

Kluyver HN, Tinbergen L (1953) Territory and the regulation of density in titmice. Arch Neerl Zool 10:265-289

Lammens JJ (1967) Growth and reproduction of a tidal flat population of Macoma balthica (L.) Neth J Sea Res 3:315-382

Meer J van der, Beukema JJ, Dekker R (2001) Long-term variability in secondary production of an intertidal bivalve population is primarily a matter of recruitment variability. J Anim Ecol $70: 159-169$

Newton I (1989) Lifetime reproduction in birds. Academic Press, London

Pulliam HR (1988) Sources, sinks, and population regulation. Am Nat 132:652-661

Scheltema RS (1986) Long-distance dispersal by planktonic larvae of shoal-water benthic invertebrates among Central Pacific islands. Bull Mar Sci 39:241-256

Tilman D, Kareiva P (1997) Spatial ecology: the role of space in population dynamics and interspecific interactions. Princeton University Press, Princeton, N.J.

Woodin SA (1991) Recruitment of infauna: positive or negative cues? Am Zool 31:797-807 